\title{
PENGELOLAAN SAMPAH PLASTIK MENJADI PRODUK KERAJINAN TANGAN
}

\section{PROCESS OF PLASTIC WASTE INTO A HANDY CRAFT PRODUCT}

\author{
Fadia Fitriyanti ${ }^{1)}$, Ani Yunita ${ }^{2)}$ \\ Hukum Bisnis,Fakultas Hukum, Universitas Muhammadiyah Yogyakarta \\ Kampus Terpadu UMY \\ Jl.Lingkar Selatan Tamantirto,Bantul \\ Yogyakarta \\ 1yantifadia@umy.ac.id \\ ${ }^{2}$ masayunita2302@gmail.com
}

\begin{abstract}
Abstrak
Lokasi desa wisata Lava Bantal menjadikan Dusun Sumber Kidul sering dikunjungi banyak para wisatawan, yang berakibat pada masalah pengelolaan sampah di Dusun tersebut. Warga masyarakat berharap adanya solusi untuk mengatasi permasalahan di sekitar desa wisata lava bantal sehingga tidak mengganggu pencemaran lingkungan desa wisata dan masyarakat sekitar. Selain itu, kerajinan yang bernilai ekonomi untuk menunjang perekonomian masyarakat sekitar. Solusi yang ditawarkan bagi permasalahan kelompok PKK adalah pendampingan pengelolaan sampah dijadikan kerajinan tangan dan sosialisasi hukum bisnis dan lingkungan bagi kelompok PKK. Metode yang ditawarkan ialah Pelatihan dilakukan dengan metode ceramah dan tanya jawab. Pendampingan dan sosialisasi hukum bisnis dilakukan dengan metode pendampingan praktek. Hasil yang dicapai adalah anggota kelompok PKK yang semula belum mengetahui dan belum dapat membuat kerajinan tangan yang berasal dari sampah layak pakai maka menjadi mengetahui dan bisa membuat kerajinan tangan yang berasal dari sampah layak pakai. Selain itu, semula sampah dikumpulkan dan dijual ke pengepul dengan harga yang murah menjadi hasil karya produk bunga dan piring plastik yang sangat berinovasi, bervariatif .Antusiasme Kelompok PKK dalam mengikuti program penyuluhan dan pelatihan sangat tinggi sehingga dapat mendukung keberhasilan proses pembuatan produk kerajinan sampah kreatif.
\end{abstract}

Kata Kunci- Pengelolaan, Produk, Sampah

\section{Abstract}

The location of the Lava Bantal tourist village makes Sumber Kidul Hamlet frequented by many tourists, that has impact on waste problems in the hamlet. The community hopes that there will be a solution to overcome the problems around the pillow lava tourist village so that it does not interfere with the environmental pollution of the tourist village and the surrounding community. In addition, handicrafts have economic value to support the economy of the surrounding community. The solution offered for the problems of the PKK group is assistance in managing waste into handicrafts and socializing business and environmental law for the PKK group. The method offered is that training is carried out by lecture and question and answer methods. Assistance and socialization of business law are carried out using the practical mentoring method. The results achieved were members of the PKK group who initially did not know and were unable to make handicrafts from suitable waste, so they knew and were able to make handicrafts from suitable waste. In addition, initially the waste is collected and sold to collectors at low prices, becoming the work of innovative, varied flower products and plastic plates. The enthusiasm of the PKK Group in participating in counseling and training programs is very high so it can support the success of the process of making creative waste craft products.

Keywords - Management, Products, Waste

\section{PENDAHULUAN}

Dusun Sumber Kidul, Desa Kalitirto, Kecamatan Berbah, Sleman, Daerah Istimewa Yogyakarta merupakan salah satu dusun yang berpotensi untuk dikembangkan menjadi dusun dalam suatu kawasan desa wisata. Di tepi sungai opak, jembatan gamblung Berbah terdapat sungai dimana di tepi sungai tersebut terdapat bebatuan yang terdapat bentuk akibat dari lava hasil erupsi lelehan yang langsung kontak dengan fluida (masa air bisa laut atau danau). Pembekuan yang cepat karena kontak dengan masa air menyebabkan mineralmineralnya tidak terbentuk dengan baik dan membentuk geometri mirip bantal sehingga disebut lava bantal.

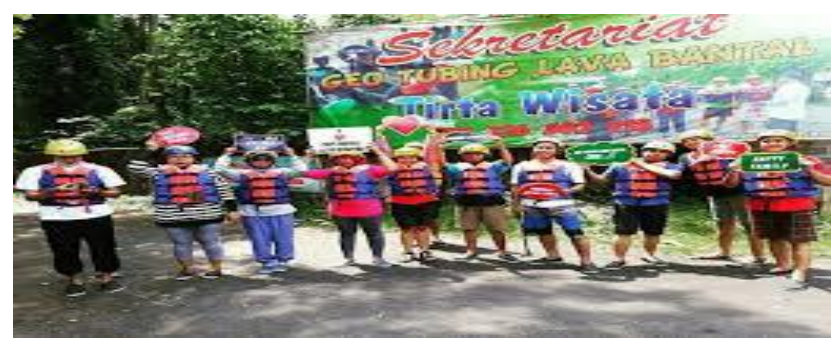

Gambar 1: Aktifitas rafting menggunakan ban di Dusun Sumber Kidul 


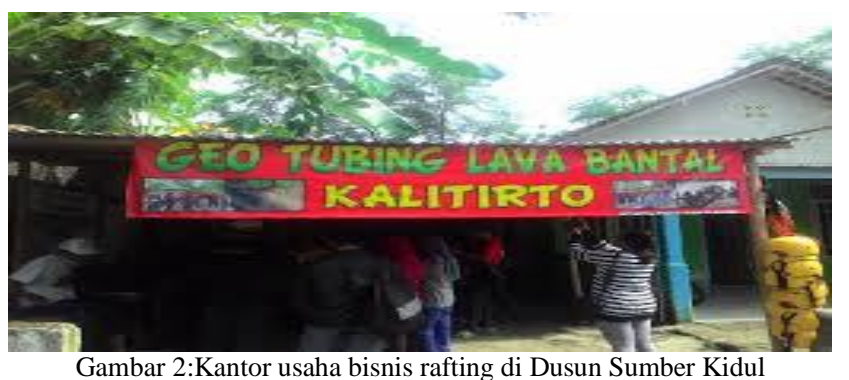

Secara Geografis Dusun Sumber Kidul merupakan salah satu Dusun yang terletak di Kelurahan Kalitirto, Kecamatan Berbah, Kabupaten Sleman. Dusun Sumber Kidul ini terletak paling selatan Kelurahan Kalitirto. Mayoritas penduduknya bermata pencaharian sebagai petani. Dusun Sumber Kidul, Kelurahan Kalitirto, Kecamatan Berbah, Kabupaten Sleman, DIY memiliki perbatasan wilayah dengan:

1. Sebelah Utara berbatasan dengan Sumber Kulon.

2. Sebelah selatan berbatasan dengan Kelurahan Tlogotirto.

3. Sebelah Barat berbatasan dengan Sumber Kulon.

4. Sebelah timur berbatasan dengan Sungai Opak/Kelurahan Jogotirto.

Dusun Sumber Kidul adalah dusun yang terletak di bagian selatan dari Kelurahan Kalitirto, Berbah. Dusun ini berjarak relatif dekat dari kantor Kecamatan Berbah, lebih tepatnya sekitar 2 kilometer ke arah Timur. Dusun ini terdiri dari 2 Rukun Warga (RW) yakni RW 32 dan RW 33 yang terbagi menjadi 6 Rukun Tetangga (RT). ${ }^{1}$ Mayoritas masyarakat di Dusun Sumber Kidul, Kelurahan Kalitirto, Kecamatan Berbah, Kabupaten Sleman, DIY memiliki mata pencaharian petani. Masyarakat di Dusun ini telah menanam singkong, jagung, kacang sebagai komoditas unggulan dan padi sebagai tanaman pangan untuk menunjang kebutuhan pangan keluarga.

Lokasi desa wisata lava bantal menjadikan Dusun Sumber Kidul sering dikunjungi banyak para wisatawan untuk melihat keindahan alam desa tersebut. Dengan adanya kunjungan para wisatawan yang ke Dusun Sumber Kidul maka berakibat terhadap masalah pengelolaan sampah di Dusun tersebut. Hal ini dikarenakan di lokasi tersebut belum dilakukan manajemen yang baik terhadap pengelolaan sampah sehingga sampah tersebut tidak dapat bernilai ekonomis. Kebanyakan sampah itu merupakan sampah plastik yang sulit didegradasikan oleh mikro organisme selain itu sampah plastik dapat bertahan hingga bertahun-tahun sehingga menyebabkan pencemaran terhadap lingkungan. ${ }^{2}$

Warga masyarakat Dusun Sumber Kidul berharap adanya solusi untuk mengatasi permasalahan di sekitar desa wisata lava bantal sehingga tidak mengganggu pencemaran lingkungan desa wisata dan masyarakat sekitar. Selain itu, kerajinan yang bernilai ekonomi untuk menunjang perekonomian masyarakat sekitar. Salah satu upaya untuk mengurangi dampak buruk sampah plastik bagi lingkungan adalah dengan melaksanakan prinsip 3R dalam kehidupan sehari-hari yaitu pengurangan pemakaian (reduce), pemakaian ulang(reuse), pendaur ulang (recycle).

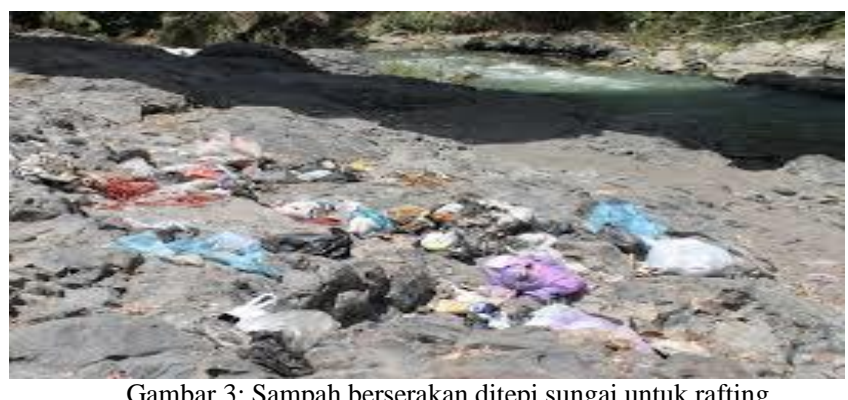

Gambar 3: Sampah berserakan ditepi sungai untuk rafting

Salah satu penanganan terhadap sampah plastik adalah dengan melakukan pendaur ulang atau recycle. ${ }^{3}$ Di Dusun Sumber Kidul terdapat kelompok Ibu-Ibu PKK yang memiliki potensi dalam membuat kerajinan sampah kreatif agar memiliki manfaat dan bernilai ekonomis. Persoalan sampah di lava bantal di tempat wisata diharapkan dapat diselesaikan melalui kegiatan pengelolaan dan pengolahan sampah menjadi barangbarang kerajinan yang bernilai ekonomi bagi kelompok ibu-ibu PKK. Selama ini, sampah yang berasal dari rumah tangga hanya dikumpulkan di rumah Ibu Dukuh dan kemudian hanya dijual ke pengepul dengan harga yang murah sehingga kurangnya pendapatan dan kas kelompok PKK Dusun Sumber Kidul. Hal tersebut dilakukan karena kurangnya pengetahuan kelompok PKK untuk membuat kerajinan tangan yang berasal dari sampah yang layak pakai sehingga tim pelaksana pengabdian berinisiatif untuk meningkatkan pengetahuan dan ketrampilan kelompok PKK dalam membuat kerajinan tangan sehingga kelompok PKK memiliki pengetahuan, hasil inovasi produk kerajinan sampah dan peningkatan pendapatan bagi kelompok PKK. Sehubungan dengan hal tersebut perlu pengelolaan sampah sebagai kerajinan tangan agar bernilai ekonomis bagi kelompok PKK dalam hal sosialisasi hukum lingkungan dan bisnis dan pendampingan pengelolaan sampah menjadi kerajinan tangan.

A. Solusi Yang Ditawarkan

Solusi yang ditawarkan dalam penerapan Pengabdian Masyarakat ini adalah: Sosialisasi mengenai hukum lingkungan dan bisnis serta pendampingan pengelolaan sampah dijadikan kerajinan tangan.

\section{TARGET LUARAN}

Target luaran yang akan dihasilkan dari kegiatan Pengabdian Masyarakat ini adalah: memberdayakan masyarakat Mitra yaitu Dusun Sumber Kidul, Desa Berbah agar menjadi dusun yang dapat secara mandiri yang dapat meningkatkan kreativitas pengolahan sampah kreatif dan dapat menghasilkan barang 
yang memiliki nilai ekonomi sehingga dapat meningkatkan perekonomian masyarakat Dusun Sumber Kidul.

\section{METODE PELAKSANAAN}

Metode yang digunakan dalam teknologi pengolahan sampah di Dusun Sumber Kidul, Berbah, Kalitirto, Sleman dibagi menjadi 2 tahap yaitu penyuluhan pengelolaan sampah dan pendampingan pelatihan pengelolaan sampah untuk dijadikan kerajinan tangan.

\section{Tahap I. Penyuluhan Jenis Sampah dan Cara Pengelolaan}

\section{Sampah}

a. Penyuluhan Pengelolaan Sampah bagi Kelompok PKK

Tahap I ini dilaksanakan untuk mencapai luaran yang pertama. Adapun kegiatan yang dilakukan pada tahap ini ialah kegiatan penyuluhan tentang jenis sampah dan cara pengelolaan sampah.

Penyuluhan ini bertujuan untuk menambah dan meningkatkan pengetahuan dan ketrampilan kelompok PKK Dusun Sumber Kidul, Berbah, Sleman dalam mengembangkan potensi usaha bersama dalam kelompok PKK sehingga diharapkan anggota dapat mandiri secara ekonomi. Dengan adanya penyuluhan kelompok PKK Dusun Sumber Kidul diharapkan dapat:

1) Meningkatkan wawasan dan pengetahuan dalam mengubah pola pikir anggota untuk menumbuhkan kreatifivitas dan jiwa kewirausahaan.

2) Mengetahui dan memahami jenis-jenis, bahaya sampah dan cara pengelolaan sampah.

3) Mengetahui mekanisme proses pembuatan kerajinan tangan.

4) Mengetahui strategi pemasaran produk.

Materi penyuluhan dikemas dengan fleksibel mengikuti kebutuhan peserta penyuluhan kelompok PKK Dusun Sumber Kidul yang berorientasi pada pencapaian tujuan yaitu meningkatkan pengetahuan dan ketrampilan dalam menghasilkan produk kerajinan tangan dan pemasaran. Penyuluhan diselenggarakan di kediaman Bu Evi sebagai Wakil Kelompok PKK di kelompok PKK Dusun Sumber Kidul secara efektif.

Dalam Program ini melibatkan narasumber atau fasilitator yang berasal dari Jogja. Narasumber yang diundang ialah orang yang memiliki kompetensi atau keahlian yang bisa mendukung pencapaian tujuan. Sasaran dari penyuluhan ini ialah anggota kelompok PKK yang berusia produktif diutamakan yang berjenis kelamin perempuan yang menganggur atau mempunyai banyak waktu luang.

Tahap 2. Pendampingan pelatihan pengelolaan sampah a. Pendampingan Pelatihan Pengelolaan Sampah Bagi

\section{Kelompok PKK}

Prosedur pengelolaan sampah untuk dijadikan produk kerajinan tangan yang akan diajarkan ialah sebagai berikut:

1) Penyortiran Sampah Kering dan Sampah Basah Sortir adalah salah satu metode untuk memisahkan sampah yang kering maupun yang basah agar sampah dapat digunakan untuk bahan kerajinan tangan dan pupuk. Sampah yang kering seperti sampah jenis plastik digunakan untuk bahan pembuatan kerajinan tangan. Peserta diajarkan cara pemilihan dan memisahkan sampah yang masih dimanfaatkan dan yang tidak bisa lagi dimanfaatkan untuk kerajinan tangan. Penyortiran segera dilakukan untuk memisahkan sampah dari tanah, pasir, maupun kotoran yang lain harus segera dibersihkan.

2) Pencucian

Setelah di sortir bahan harus segera dicuci dan dibersihkan dengan menggunakan air bersih seperti air dari mata air, sumur dan atau PAM. Cara pencucian dapat dilakukan dengan cara perendaman.

Perendaman tidak boleh terlalu lama warna dari jenis plastik sampah tersebut tidak pudar.

3) Pengeringan

Pengeringan adalah suatu metode untuk memisahkan air dari bahan plastik dengan menggunakan sinar matahari. Pengeringan tidak boleh terlalu lama sebab bahan jenis plastik tidak boleh dilakukan pengeringan terlalu lama yang akan menyebabkan pengerutan pada bahan plastik tersebut.

4) Pengolahan

Pengolahan adalah metode pembuatan bahan plastik tersebut dengan cara dijahit atau disetrika dan dibentuk dengan model bervariasi seperti tas, bunga, kotak pensil, piring plastik, wadah botol minum, dan sebagainya sehingga memiliki nilai jual ke masyarakat.

\section{Faktor Pendukung dan Penghambat}

Berikut ini terdapat faktor pendukung dan penghambat selama pengabdian masyarakat ialah sebagai berikut:

1) Faktor Pendukung Antusiasme kelompok PKK dalam mengikuti program penyuluhan dan pelatihan.

2) Faktor Penghambat Permasalahan atau kendala dalam kegiatan pengabdian ini antara lain sebagai berikut

a) Alat untuk membuat produk kerajinan sampah masih sangat terbatas.

b) Kurangnya modal untuk pembelian bahan produk kerajinan sampah.

\section{IV.HASIL DAN PEMBAHASAN}

Hasil dan pembahasan dalam pelaksanaan pengabdian masyarakat ini meliputi:

1.Tahap Persiapan

Tujuan program ini bertujuan untuk memberdayakan masyarakat Mitra yaitu Dusun Sumber Kidul, Desa Berbah agar menjadi dusun yang dapat secara mandiri yang dapat meningkatkan kreativitas pengolahan sampah kreatif dan dapat menghasilkan barang yang memiliki nilai ekonomi sehingga dapat meningkatkan perekonomian masyarakat Dusun Sumber Kidul. Pemberdayaan masyarakat adalah 
suatu proses dimana masyarakat mampu meningkatkan pemahamannya secara mandiri. Dalam proses ini, tim pelaksana pengabdian berperan sebagai fasilitator yang mendampingi proses pemberdayaan masyarakat, yang pada prinsipnya masyarakatlah yang menjalankan program akan tetapi usulan-usulan masyarakat merupakan dasar bagi program. Aspek penting dalam suatu program pemberdayaan masyarakat ialah program dan strategi yang disusun sendiri oleh masyarakat. Ini berawal dari program kegiatan mahasiswa KKN 060 UMY pada tahun 2017 mengenai Pendampingan Masyarakat di Wisata Lava Bantal, dimana pelaksana menjadi DPLnya. Diwisata Lava Bantal banyak ditemukan sampah yang berserakan ulah para pengunjung wisatawan yang tidak tertib menjaga kebersihan. Jadi kegiatan program PKM ini sesungguhnya merupakan lanjutan dari kegiatan program KKN mahasiswa. Sebelum kegiatan pengabdian, Tim pelaksana pengabdian berkunjung kerumah pak Dukuh pada tanggal 24 Februari 2019 Dusun Sumber Kidul, Berbah, Sleman sekaligus menemui Ibu Ketua PKK, Ibu Hidayati Nur Aisyah.

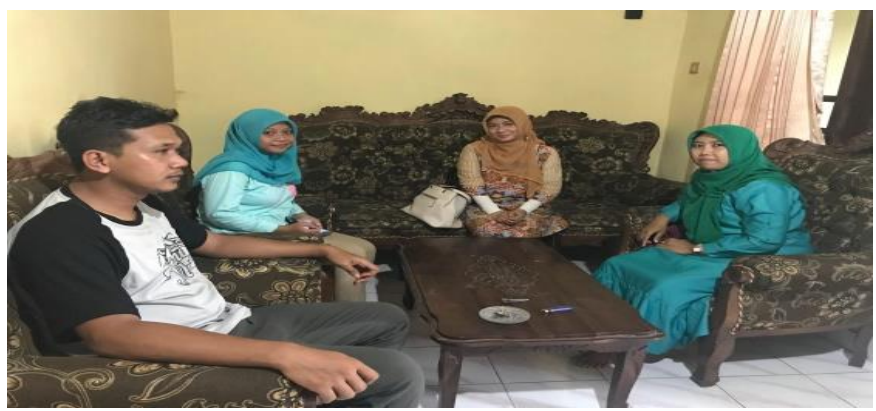

Gambar 4:Kunjungan kerumah Pak Dukuh Dusun Sumber Kidul

\section{Tahap Pelaksanaan Program}

Untuk mencapai keberhasilan pada tahap pelaksanaan program maka dilaksanakan program penyuluhan dan pelatihan pembuatan sampah kreatif sebagai berikut:

a.Program Penyuluhan

Program penyuluhan ini dilaksanakan dengan mengundang narasumber dari salah satu Pengelola sampah Gemah Ripah yang bernama Ibu Lastri. Peserta penyuluhan ini yaitu Kelompok PKK Dusun Sumber Kidul. Program ini bertujuan untuk memberikan pengetahuan tentang jenis, manfaat sampah dan bahaya sampah kepada Kelompok PKK Dusun Sumber Kidul. Program penyuluhan ini berlangsung selama 2 (dua) jam yang diadakan di rumah kediaman Bu Evi selaku wakil ketua Kelompok PKK Dusun Sumber Kidul, Berbah, pada tanggal 10 Maret 2019 jam 13.00 sd jam 15.00. Pelatihan ini dihadiri oleh anggota kelompok PKK yang berusia antara 30-50 tahun sebanyak 40 anggota PKK. Ibu lastri memaparkan beberapa materi berkaitan dengan pemanfaatan sampah kreatif kepada anggota Kelompok PKK. Kelompok PKK sangat antusias dan responsif dengan pemaparan materi tersebut. Kelompok PKK sangat memerlukan penyuluhan tersebut dikarenakan pengetahuan mengenai sampah kreatif sangat terbatas. Dengan adanya penyuluhan tersebut maka Kelompok PKK mendapatkan pengetahuan mengenai jenis sampah, bahaya sampah dan pemanfaat sampah yang dapat dimanfaatkan menjadi sampah kreatif.

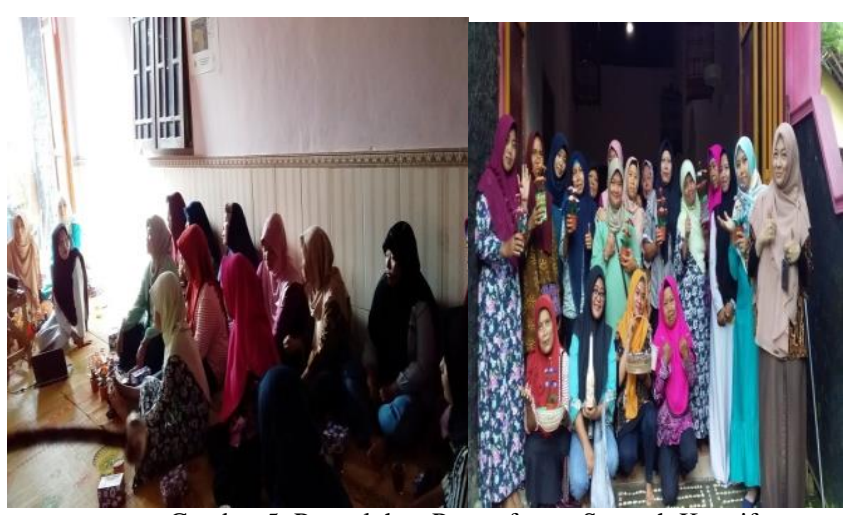

Gambar 5: Penyuluhan Pemanfaatan Sampah Kreatif

a.Program Pelatihan Pembuatan Kerajinan sampah kreatif Program pelatihan ini diadakan pada tanggal 17 Maret 2019 jam 15.00 sd jam 17.00 wib, di salah satu kediaman anggota kelompok PKK Dusun Sumber Kidul. Pelatihan ini mengundang pelatih dari bank sampah gemah ripah yaitu Ibu lastri dan Ibu Yuli yang dihadiri oleh anggota kelompok sebanyak 40 peserta anggota kelompok PKK. Anggota kelompok PKK sangat antusias dan terampil dalam membuat kerajinan sampah kreatif. Pelatihan ini berlangsung selama 2 jam. Sebelum pembuatan kerajinan sampah kreatif dibuat, Pelatih menjelaskan cara-cara pembuatan kerajinan sampah terlebih dahulu. Anggota kelompok PKK membuat bungabunga yang berwarna-warni dan membuat piring plastik yang sangat indah. Tim Pelaksana Pengabdian PKM juga ikut serta dalam proses pembuatan kerajinan sampah kreatif bersama anggota kelompok PKK sehingga program dapat berjalan baik dan lancar

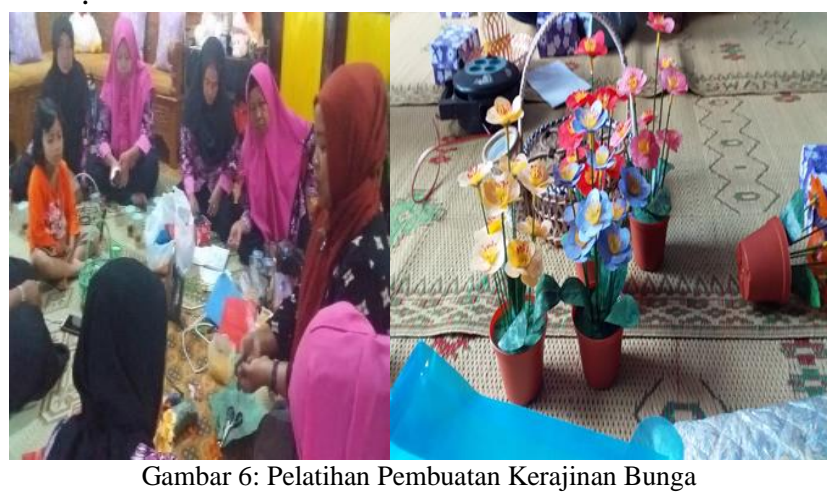




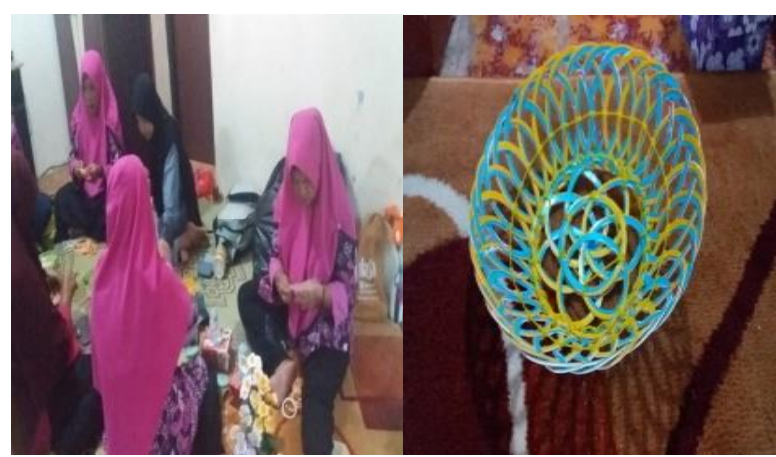

Gambar 7: Pelatihan Pembuatan Kerajinan Piring Plastik

c. Pendampingan Program

Selain dilakukannya program penyuluhan dan pelatihan produk kerajinan sampah kreatif, juga dilakukan pendampingan kegiatan yang dilakukan oleh tim pelaksana pengabdi untuk memonitor dan mengevaluasi program kegiatan sehingga mengetahui kendala-kendala dan capaian kegiatan.

\section{KESIMPULAN}

Pelaksanaan Program Pengabdian Masyarakat di Dusun Sumber Kidul, Desa Kalitirto, Kecamatan Berbah, Kabupaten Bantul merupakan serangkaian kegiatan yang saling berhubungan antara pelaksana dan mitra dimana hasil kegiatan berjalan dengan baik dan lancar. Anggota kelompok PKK Dusun Sumber Kidul yang semula belum mengetahui dan belum dapat membuat kerajinan tangan yang berasal dari sampah layak pakai maka menjadi mengetahui dan bisa membuat kerajinan tangan yang berasal dari sampah layak pakai. Selain itu, Anggota PKK yang semula sampah dikumpulkan dan dijual ke pengepul dengan harga yang murah menjadi hasil karya produk bunga dan piring plastik yang sangat berinovasi, bervariatif dan sampah kreatif memiliki nilai jual yang tinggi untuk keperluan rumah tangga khususnya di Dusun Sumber Kidul, Berbah dan masyarakat luas pada umumnya. Antusiasme Kelompok PKK dalam mengikuti program penyuluhan dan pelatihan sangat tinggi sehingga dapat mendukung keberhasilan proses pembuatan produk kerajinan sampah kreatif. Permasalahan yang dihadapi oleh mitra bisa diatasi secara optimal dari aspek pembuatan sampah kerajinan kreatif. Dengan adanya pengabdian ini maka memberikan nilai tambah terhadap sampah yang semula masih banyak yang dibuang dan tidak dimanfaatkan oleh masyarakat menjadi sangat bermanfaat dengan bentuk produk bunga dan piring plastik sehingga memiliki nilai jual tinggi.

\section{A. Saran}

1. Perlu ditingkatkan pemahaman dan ketrampilan pembuatan jenis sampah kreatif yang lainnya.

2. Masih diperlukan pendampingan yang berkesinambungan untuk keberlanjutan program terutama mengenai pembuatan kerajinan sampah kreatif.
3. Setelah adanya pengabdian masyarakat ini sebaiknya ditindaklanjuti dengan melakukan pemasaran produk sampah kreatif.

\section{UCAPAN TERIMAKASIH}

Penulis mengucapkan terimakasih kepada Lembaga Penelitian, Publikasi dan Pengabdian Masyarakat Universitas Muhammadiyah Yogyakarta yang mendanai penelitian ini, kelompok PKK Dusun Sumber Kidul, Kelurahan Kalitirto, Desa Berbah, Sleman, Daerah Istimewa Yogyakarta yang banyak membantu terselenggara pengabdian ini.

\section{DAFTAR PUSTAKA}

[1] Anonim, diakses di http://kampunganggrekkalitirto.blogspot.com/p/dusunsumber-kidul.html pada tanggal 10 Mei 2019.

[2] Anonim, https://www.maxmanroe.com/vid/umum/pengertian-samph.html Pengertian Sampah: Jenis, Dampak, dan Cara Penanganannya diakses pada tanggal 17 Mei 2019.

[3] Muchlisin Riadi ,https://www.kajianpustaka.com/2015/02/pengertianjenis-dan-dampak-sampah.html. Diakses pada tanggal 16 Mei 2019.

Hayat, Hasan Zayadi. 2018. Model Inovasi Pengelolaan Sampah Rumah Tangga, Jurnal Ketahanan Pangan, Volume 2, Nomor 2, Desember 2018, pp. 136.

[4] Hijrah Purnama Putra dan Yebi Yuriandala. 2010. Studi Pemanfaatan Sampah Plastik Menjadi Produk dan Jasa Kreatif, Jurnal Sains dan Teknologi Lingkungan, Vol 2 Nomor 1, Januari 2010,ISSN:2085-1227, pp 23

[5] Nur Fatoni dkk. 2017. Pendayagunaan Sampah Menjadi Produk Kerajinan, UIN Walisongo Semarang, DIMAS, Volume 17, Nomor 1, Mei 2017 , pp. $87-88$.

[6] Nurhenu Karuniastuti, Bahaya Plastik terhadap Kesehatan dan Lingkungan", Forum Teknologi, vol 3 Nomor 1,pp 1 